\title{
Early Childhood Education and Care in a Post- pandemic Economy: Lessons from China
}

\author{
Jincheng $\mathrm{Ma}^{*}$ and Lei Guo \\ Beihang University, Beijing, China
}

\begin{abstract}
The mismatch between the demand side and the supply side in the Early Childhood Education and Care (ECEC) sector has been a recurring pattern for a long period of time. Unlike the other levels and types of education, over $60 \%$ of provision in the ECEC sector comes from private organizations in China. Following the outbreak of the coronavirus pandemic in 2020, challenges have emerged in the high-level customer contact services and the classic labour-intensive industries. From the "regular epidemic prevention and control" point of view, regulatory reform is necessary, such as translating the "price cap regulation" into the "rate of return regulation", enforcing the demand side incentive, combining regulatory innovation and technical innovation, and creating good conditions for the professional development of teachers in the ECEC sector. Keywords: ECEC, Post-pandemic Economy, Human Capital, Regulation.
\end{abstract}

\section{Introduction}

The Early Childhood Education and Care (ECEC) sector is important for the reconciliation of work and family life, especially for developing countries. It will at once be evident that women get more benefit from enlarging the scale of public investment in the early stages, as the gender-equitable labour participation on a full-time and universal basis will reach a higher plane. From the demographic point of view, some researchers argue that the cost of ECEC is invisible and a hard curb on a family's desire to have a baby, since the ECEC sector can influence the direct and/or indirect costs of having children [2]. What's more, the core idea of increasing formation of early stage human capital such as focusing on disadvantaged families, and focusing more on prevention rather than on compensation, has undoubted significance for alleviating poverty in modern society [6].

However, the outbreak of COVID-19 has plunged the global economy into a sudden and unprecedented recession. This crisis will catalyse some huge changes, and few industries will avoid reform, restructure or removal. In this paper, we will review the challenges in the ECEC sector in a post-pandemic economy, taking China as an example, and then put forward several suggestions.

\section{The supply side of the ECEC sector in China}

\footnotetext{
* Corresponding author: majincheng0901@gmail.com
} 
Economic transition brought about huge changes in the social service sector in China at the end of the 20th century. In particular, several state welfare systems were abolished in order to raise economic efficiency, however, the provision of social services also declined gradually. In the ECEC sector, approximately $50 \%$ of children entered primary school without any pre-school education experience in the first decade of this century in China. This situation was criticized by many scholars in China and abroad, including the 2000 Nobel laureate James J. Heckman [5]. When policymakers in China realized the seriousness of situation, a 10 -year-plan was enacted in 2010, causing the enrolment rate to rise sharply. By the end of 2019 , the enrolment rate in preschool education reached $83.4 \%$. But, for children aged 3 years and below, enrolment to formal childcare is $4.1 \%$, compared with average $34 \%$ in OECD countries [8].

Another characteristic of the ECEC sector in China is that private organizations consist a large proportion of the suppliers. Table 1 below shows that no less than $60 \%$ of supplies in the ECEC sector in China are private organizations, which is very different from what situation in primary, secondary and higher education across the country. From the demand side, it may seem that urbanization is underlying reasons for this situation, but in fact the rating of budget priority of the ECEC sector of local governments under the fiscal system of decentralization is key. It is the incentive non-compatibility in the public sector at work.

Table 1. The ECEC enrolment and private ratio in China.

\begin{tabular}{|c|c|c|c|c|c|c|}
\hline year & $\begin{array}{l}\text { Facilities } \\
\text { [national] } \\
-1\end{array}$ & $\begin{array}{l}\text { Facilities } \\
\text { [private] } \\
(2) \\
\end{array}$ & $\begin{array}{l}\text { Enrolment } \\
\text { [national] } \\
\text { (3) }\end{array}$ & $\begin{array}{l}\text { Enrolment } \\
\text { [private } \\
\text { facilities] } \\
\text { (4) }\end{array}$ & $\begin{array}{l}\quad \text { private } \\
\text { ratio(children) } \\
(4) /(3)\end{array}$ & $\begin{array}{l}\quad \text { p private } \\
\text { ratio(facilities) } \\
(2) /(1)\end{array}$ \\
\hline 2010 & 150400 & 102289 & 29766700 & 13994700 & $47.01 \%$ & $68.01 \%$ \\
\hline 2011 & 166800 & 115404 & 34244500 & 16942100 & $49.47 \%$ & $69.19 \%$ \\
\hline 2012 & 181300 & 124600 & 36857600 & 18527400 & $50.27 \%$ & $68.73 \%$ \\
\hline 2013 & 198600 & 133500 & 38946900 & 19902500 & $51.10 \%$ & $67.22 \%$ \\
\hline 2014 & 209900 & 139300 & 40507100 & 21253800 & $52.47 \%$ & $66.36 \%$ \\
\hline 2015 & 223700 & 146400 & 42648300 & 23024400 & $53.99 \%$ & $65.44 \%$ \\
\hline 2016 & 239800 & 154200 & 44138600 & 24376600 & $55.23 \%$ & $64.30 \%$ \\
\hline 2017 & 255000 & 160400 & 46001400 & 25723400 & $55.92 \%$ & $62.90 \%$ \\
\hline 2018 & 266700 & 165800 & 46564200 & 26397800 & $56.69 \%$ & $62.16 \%$ \\
\hline 2019 & 281200 & 173200 & 47138800 & 26494400 & $56.21 \%$ & $61.59 \%$ \\
\hline
\end{tabular}

Sources: National educational development statistical bulletin. Information on http://www.moe.gov.cn/jyb_sjzl/sjzl_fztjgb.

The third characteristic of the ECEC sector in China is that it is a classic labour-intensive industry. The proliferation of information technology and Artificial Intelligence (AI) in the ECEC sector is much slower than in any other stage of education. As employee costs consist of the major part of the overall cost in the ECEC sector, the ECEC industry is vulnerable to "the Baumol cost disease". What's worse is that the regulation is something like a "PriceCap", which can enhance productivity in a capital-intensive industry but has the disincentives to invest in a human service industry. For a labour-intensive industry, "inherent in the technological structure of each of these activities are forces working almost unavoidably for progressive and cumulative increases in the real costs incurred in supplying them" [3]. If the regulation authority keeps the price down, while this may succeed temporarily, service quality will diminish in the long run. 


\section{Some challenges}

The coronavirus pandemic has plunged the global economy into a sudden and unprecedented recession. All kinds of occupancies such as cinemas, gymnasiums, and schools have closed following national lockdowns. Businesses who aren't able to make use of solutions such as the potential of cloud computing have lost huge portions of their revenue. In the summer, with the coronavirus gradually under control in China, high-level customer contact services have started to resume business.

Pre-school education has been the last service to resume among all levels and types of education in China. Across the country, most local kindergartens reopened after "the winter vacation" in June. During this "extra-long winter vacation", public organizations have been relatively less affected because their costs are covered by governmental expenditure. However, private organizations are not only unable to collect tutoring fees in advance under policy constraints, but they also need to continue to pay teachers' salaries and housing rents during the winter vacation, thus these organizations have experienced an unprecedented "hardest winter and spring" as the media says.

As many teachers in private organizations have only received partial wages or even no wages at all, a large number of teachers in private organizations have resigned or changed jobs during this period, especially the male teachers. In addition, even after the resumption of work in June, due to the smaller number of children returning to kindergartens, a considerable number of teachers are idle. Teachers who have been laid off or resigned have begun to start their own "micro businesses".

Of course, some teachers in private organizations do not want to end their careers and they are actively seeking new ways of survival. The typical approach of private organizations has been to start "side-line production" whereby some private organizations are using their own catering facilities to organize teachers to start the production of take-out meals; some private kindergartens with ample outside space are even selling barbecue food in the evening and night.

In April, when the resumption of work was still unclear, a survey in western China revealed reduction in student resources, loss of teachers, and rent pressure were the three main impacts of the pandemic on private kindergartens, which had severely hit supply organizations. The loss of teachers brings unfavourable expectations to upstream students in the normal colleges and universities, leading to weak follow-up development.

\section{Conclusion and suggestions}

From the education point of view, there seems to have been no basic law to abide by in the ECEC sector in China until now, and the mismatch in the demand and supply side in this sector has been a recurring pattern for a long period of time. This mismatch goes even badly after of the coronavirus epidemic outbroke this year. It deteriorated not only many private kindergartens' on the brink of financial catastrophe, but has also had an adverse impact on the industrial chain, for example, some children's products for intellectual development and physical fitness are under-operated. From the macro-economic point of view, the closure of kindergartens has also hindered women from going out for employment, and has adversely affected Chinese women's willingness to bear children. Therefore, legislation on the preschool stage of education in China is an urgent need. 


\subsection{Other suggestions}

\subsubsection{Entry regulation reform}

Service organizations in the ECEC sector in China are relatively large and monotonous, and such large kindergartens may not satisfy the heterogeneity of the demand side in China. In contrast, in the United Kingdom, in addition to pre-kindergartens and kindergartens, there are other facilities such as Family Child Care Homes and Group Homes and Group Home Providers [7]. These small-and-micro-providers are scarce in China and applicants to provide ECEC services in the country must meet certain standards such as scale and number of classrooms to be accepted. In fact, mass employment is something concern with the smalland-micro-provider when the policy focus on "ensuring stability in employment, financial operations, foreign trade, foreign investment, domestic investment, and expectations". In the upcoming long-term period of "regular epidemic prevention and control", regulations must be reformed to foster pro-heterogeneity organizations, which can respond with agility to unexpected risks.

\subsubsection{Translate the price cap regulation into the rate of return regulation (RORR)}

The ECEC service is a kind of credence goods, and is vulnerable to "the Baumol cost disease". Generally speaking, credence goods have the characteristic that though consumers can observe the utility they derive from the good ex post, they cannot judge whether the type or quality of the good they have received is the ex ante one they needed. Moreover, consumers may even ex post be unable to observe which type or quality they actually received. An expert seller, however, is able to identify the type or quality that fits a consumer's needs by performing a diagnosis [4]. When the price of these goods is tightly controlled by the regulatory authority, the quality of the service may deteriorate. In such a context, low-quality organizations can drive out high-quality organizations in the market as they can secretly lower their service cost, thus Gresham's Law also works in the ECEC sector. When turn for the RORR, under the disclosure mechanism, consumers will get what they pay for; and the "Averch-Johnson effect" [1] under the RORR will also attract investment from private sector.

\subsubsection{Enforce demand side incentive, especially the taxation incentive}

A scientific incentive mechanism will yield twice the result with half the effort. The role of clients in monitoring providers can be strengthened by increasing choice on the demand side and increasing participation in service delivery. Indeed, "when clients are given a choice among service providers, they reveal their demand by 'voting with their feet' " [9]. Some local governments in China subsidize preschool services in the form of vouchers, but offer taxation deduction only for the cost of at age 3-5, and there is no tax credit until now. As the childcare tax deduction and credit are primarily designed to provide local governments financial relief and to avoid a fragmented child care subsidy system, the public funding of the ECEC sector should mainly via the tax method. However, any policy must be credible, as long-term incentives will yield stable expectation.

\subsubsection{Technical innovation}

In a recent article, the president of a global technology firm asked an important question: "Who will be the winners in a post-pandemic economy?". His analysis was that the success 
of various types of services hinged on their ability to cope with three key factors: (1) "Businesses that use cloud computing will not buckle under the pressure of the coronavirus pandemic"; (2) "Further automation and artificial intelligence will enhance the resilience of supply chains"; and (3), "Successful businesses will have a combination of resilience and agility." Clearly, the prohibition of online courses impairs the providers' operational capacity in "regular epidemic prevention and control" circumstances. COVID-19 will force a rebirth of many high-level customer contact service industries, as people are forced to remain at home during a lockdown. Thus, regulations must innovate and use the right technology. In the future, ECEC services must rely on the internet and use more artificial intelligence. Perhaps a revolution in the ECEC sector is looming, when childcare services become a distributed system, and providers can service clients remotely.

\subsubsection{Finally, authorities in China should create good conditions for the professional development of the teachers.}

"Teachers are the foundation of teaching and the source of developing education", and teachers are also core assets and the lifeblood of a kindergarten. However, in recent years, private organizations have faced the dual dilemma of teacher recruitment difficulties and teacher turnover. Generally, heavy workloads, lower salaries and obstacles in career development have been the main causes for teachers to leave the profession. Thus, measures should be focus on several key factors, such as making the starting salaries for teachers among the most competitive in the graduate labour market, building on above-inflation average pay increases for teachers, and ensuring that teachers are in no doubt that the government fully supports them in every stage of their career.

\section{References}

1. H. Averch, L. L. Johnson, Am. Econ. Rev., 52, 1053(1962)

2. G. S. Becker, Conference of the Universities-NBER, Princeton, N.J.: Princeton University Press, 209(1960)

3. W. J. Baumol, W. G. Bowen, Am. Econ. Rev., 55, 495 (1965)

4. U. Dulleck, R. Kerschbamer, M. Sutter, Am. Econ. Rev., 101, 526(2011)

5. J. J. Heckman, China Econ. Rev., 16, 50 (2005)

6. L. Guo, J. Qu, Econ. Perspectives, 116(2019).

7. E. C. Melhuish, International J. of Child Care and Educ. Policy, 10, 1 (2016)

8. K. Müller, K. Wrohlich, Lab. Econ., 62, 1(2020)

9. World Bank, World Bank Report, No. 53746-CN (2011) 